Original Article

\title{
INVESTIGATING FUTURE PHARMACISTS UNDERSTANDING OF VACCINES AND MYTHS SURROUNDING VACCINATION
}

\author{
SIDRAH ZAHID, HANA MORRISSEY, PATRICK BALL \\ University of Wolverhampton, School of Pharmacy, United Kingdom \\ Email: hana.morrissey@wlv.ac.uk
}

Received: 13 Jun 2020, Revised and Accepted: 16 Aug 2020

\begin{abstract}
Objective: The United Kingdom has lost its measles, mumps and rubella free status due to a decline in vaccination uptake. There are several beliefs such as safety concern and media influence that discourage people from having vaccinations. To identify gaps in knowledge of vaccination within 3 rd year pharmacy students, and to observe whether they can spot myths about vaccines, in particular the measles, mumps and rubella vaccine.

Methods: A questionnaire-based approach was used after gaining ethical approval which included a range of open and closed questions.

Results: None of the participants could identify the six common myths reported by the World Health Organisation and $40 \%$ failed to accurately identify the type of vaccine of the measles, mumps and rubella vaccine. There were clear gaps in knowledge on vaccines in participants particularly from black, Asian and minority ethnic group participants compared to white students. Educating participants about the myths could have positive future implications on their scientific knowledge when they work as pharmacists.
\end{abstract}

Conclusion: Many students did not accurately identify the myths surrounding vaccines and were provided informative leaflets to enhance their scientific knowledge. The gaps in knowledge identified, demonstrates that further teaching sessions should be implemented to cover the grey areas, allowing them to appropriately recommend vaccinations in the future.

Keywords: Vaccination, Measles, Mumps and rubella, Autism, Halal, Animal and blood free vaccines

(C) 2020 The Authors. Published by Innovare Academic Sciences Pvt Ltd. This is an open access article under the CC BY license (http://creativecommons.org/licenses/by/4.0/) DOI: http://dx.doi.org/10.22159/ijcpr.2020v12i5.39778. Journal homepage: https://innovareacademics.in/journals/index.php/ijcpr

\section{INTRODUCTION}

Measles, mumps and rubella are three highly contagious viral diseases. These viruses can cause symptoms such as fever, headache, muscle pain, aching joints, and rash [1]. Contracting any of these conditions can have life-changing implications such as measles encephalitis, leading to brain injuries, hearing loss and immune suppression [2]. The combined vaccine known as measles, mumps and rubella (MMR) vaccine was first produced in 1971 and made widely available to promote widespread herd immunity to these diseases. The MMR vaccine is a live, attenuated vaccine; there are two types of MMR vaccines and both include live, weakened strains of the measles, mumps and rubella virus [3]. (Stewart, 2020) One formulation contains porcine gelatine as a stabiliser, thus does not comply with a halal or kosher requirements. The other is a suitable alternative for patients who follow Muslim or Jewish beliefs [3].

The first dose of the MMR vaccine is recommended to be administered shortly after the child's first birthday, with the second dose ideally administered at $3 \mathrm{y}$ and 4 mo, just before commencing school. These two doses are generally sufficient for lifetime protection. However, females of child-bearing age susceptible to rubella and who did not have childhood vaccination may receive the full MMR vaccination doses before pregnancy but should avoid pregnancy for at least one month after the second dose [4]

A single dose of the MMR vaccine has proven to be $95 \%$ effective against measles, $64 \%$ effective against mumps and $98 \%$ effective against rubella [5, 6]. Harling, et al. (2005) and Yung, et al. (2011) reported that two doses provided superior protection to a single dose; immunity against mumps increased from $64 \%$ to $88 \%$. To reduce infection spread, herd immunity is required $[7,8]$. This occurs when a large percentage of a community has either had the disease or been vaccinated. The World Health Organization (WHO) recommends a target of at least $95 \%$ MMR vaccination uptake in a community will eliminate the possibility of infection spreading [9] WHO declared the UK measles, mumps and rubella's infection-free in 2017, however, the country failed to maintain this status, and in
2019 was stripped of this title due to an increase in the number of measles cases [10]. This was due to a decline in the vaccination uptake between 2018 -2019 where only $90.3 \%$ of the population had received their MMR first dose [11]

There has been a rising anti-vaccination movement doubting the safety and efficacy of vaccinations in general in preventing diseases. Social media has become a platform for sharing pseudoscience, where statements of falsified data, myths and opinions, have caused confusion and fear amongst the population [12]. Wakefield et al. (1998) claimed a link between the MMR vaccine and autism [13]. Despite this being disproved in 1999, vaccination uptake continued to decline, and this myth continues to be a concern amongst parents [14]. There are many myths regarding vaccines that are shared regularly including the idea that vaccines cause life-long side effects that are unknown and that having different vaccines at the same time can lead to interactions, increasing the likelihood of adverse reactions [15]. It is therefore strongly advised by WHO that health care professionals are aware of these myths and can refute them with accurate responses using their scientific knowledge, whilst encouraging vaccine uptake, in order to help reduce the spread of disease.

\section{Possible reasons for parent's vaccines refusals}

\section{Religious beliefs}

Religion impacts the decision-making process for individuals. Muslim and Jewish parents had declined the MMR vaccine due to its porcine gelatine content, which goes against their religious boundaries [16] Jehovah's witnesses reject vaccinations due to the use of animal blood cells during production, which are then injected into humans. To their belief, this is equivalent to eating or transfusing blood and is forbidden as part of the old testament. Despite the ruling being reversed by some scholars in the late 1900 s, some parents have continued to refuse vaccines, including the MMR [17].

\section{Personal opinions}

Some parents believe the risk of serious complications associated with contracting disease is minimal. Conversely a parent claimed 
they had not heard of anybody dying from the MMR vaccine, and they do not see it as a threat. Another parent believed "vulnerable children are those who do not have a good diet or come from a poorer background" [18]. Some vegans have expressed concern due to the use of animal products during production of the vaccine and trials performed on animals. Some believed two years of breastfeeding promoted immunity and believed they consequently did not need vaccines $[16,19]$. Parents believed it is important to develop their child's immunity 'naturally' and one parent claimed there is a "Positive benefit to child's actually have those illnesses properly, not a kind of half-hearted thing after the vaccination" [16]. Some spoke in terms of 'Too many chemicals in one go are not good for the immune system.' Others argued that administering three antigens at once is 'unnatural and harmful.' Parents had a view that immune overloading suppresses immune system rather than boosting it; the opposite of the vaccine's intention [18].

\section{Media influence}

Media coverage on health conditions related to vaccines are frequently mentioned by parents as a factor in their decision-making process. Hilton et al. (2006) found some parents claimed they had read surveys on social media where children vaccinated with MMR were five times more susceptible to getting asthma. Although many of these stories are opinion based and have not being conducted as formal trials, they can cause controversy $[16,17]$.

\section{Government mistrust}

Government promoted public health disease prevention programmes play a major role in promoting healthcare services Parents have been found to be less likely to trust government guidelines, facts and parent information sheets surrounding MMR vaccine uptake, due to mishandling of previous issues raised by Wakefield et al. (1998). There is a general belief that the government's priority is to reduce the likelihood of an epidemic, with superficial information regarding safety, moreover, they are considered insufficiently reassuring on the impact the vaccine would have on their children [19]

Reassurance from the Department of Health are viewed with scepticism and participants had further questions regarding their 'facts' and believed their concerns have previously not been adequately addressed [19]. Hilton et al. (2007) found parents believed that the government put the interests of pharmaceutical companies before the safety of patients, as they may have a vested interest [20]

\section{Information from health care professionals}

Parents expressed a desire to be more informed and to have open discussions with health professionals about MMR without being made to feel like a 'nuisance' or 'neurotic mother' [16]. Parents believe that doctors and health care professionals should have all the facts in order to promote knowledge on vaccine safety [20]. Parents showed trust in health care professionals and turned to pharmacists and doctors for scientific knowledge before agreeing to a vaccination, rather than government advice [19].

Clearly there is a great deal of information and mis-information and parents look to their healthcare professionals to be informative, to have knowledge on controversies and be able to combat the myths with science and evidence to regain public trust in vaccines. A pharmacist is at the frontline of healthcare, and often the first place patients visit when they have questions regarding medicines.

The aim of this study was to identify whether pharmacy students were aware of myths surrounding vaccines, and if they were able to identify myths from facts, assess their knowledge on the MMR vaccine, their opinion on vaccination, and how they would feel advising others to receive vaccination.

\section{MATERIALS AND METHODS}

Pharmacy students are the future generation of pharmacists; therefore, it is important to ensure that their curriculum and personal development plans include controversial topics such as vaccines, to adequately prepare them for future work.

A questionnaire-based study was undertaken where all third-year pharmacy students were approached as they had completed the infection diseases component of their pharmacy degree syllabus. Prior to conducting this survey, ethics approval was obtained from the Pharmacy School Ethics Board. Students were briefed about the survey prior to its distribution. Consent was implied by returning the completed questionnaire. All responses were anonymous.

The questionnaire included both open and closed questions. Students were allowed $20 \mathrm{~min}$ to complete the questionnaire. Microsoft Excel ${ }^{\mathrm{TM}}$ was used to collate and analyse the data.

\section{RESULTS}

A total of 75 completed questionnaires were collected from students. First three questions collected demographic data. The majority $(65 \%)$ of participants were females which is similar to the pharmacy profession globally. The majority $(82 \%)$ of participants were between the age of 17 and 25, only $13 \%$ were at age of $26-30 \mathrm{y}$ and $5 \%$ at age between $31-40$. There were only $9 \%$ of participants from Caucasian background, and the remaining were from a Black, Asian and minority ethnic (BAME) groups background (43\% Asian, 13\% black, $15 \%$ from Middle East) and 20\% preferred not to say).

Question 4 was designed to ask about participant's vaccination status (fig. 1). There were $41 \%$ of male participants had received the HPV vaccine and $76 \%$ of all females. This has been available on the NHS since 2018 and is routinely offered at sexual health clinics since 2008. Out of females who did not have HPV vaccinations, $84 \%$ of were of black, middle eastern or Asian descent. One female participant said she had 'refused the HPV vaccine due to not being sexually active'. There were $75 \%$ of white participants had not received the BCG vaccine, in comparison, $83 \%$ of BAME origin. None of the male participants had received all the vaccines in question 4 , and only $20 \%$ of female participants had received all the vaccines listed.

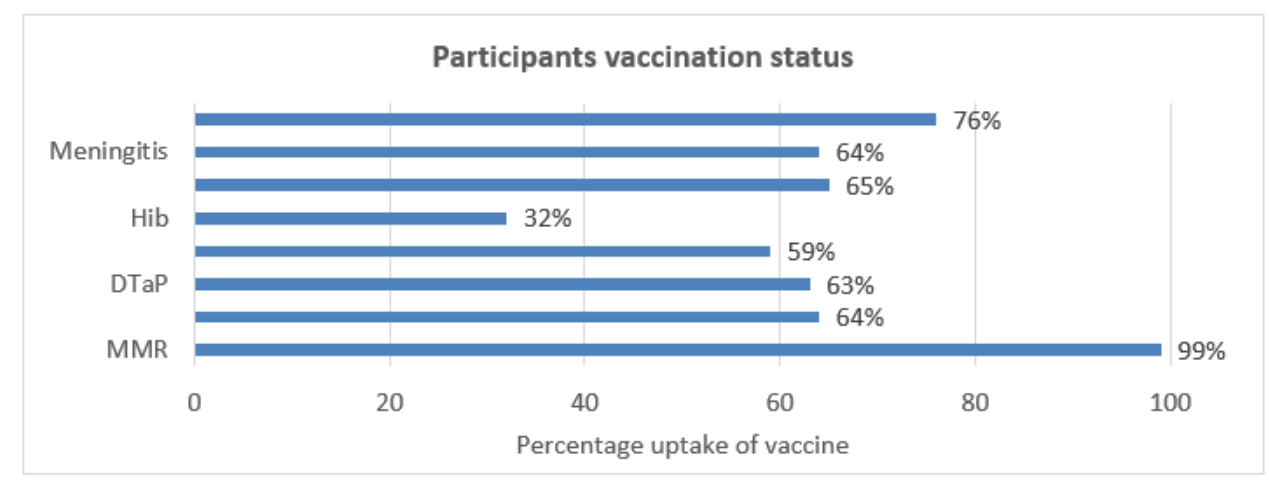

Fig. 1: Percentage of participants who have previously had the vaccines stated 
Question 5 enquired about previously rejected vaccinations, and why a vaccine was rejected. Only $13 \%$ of participants had previously rejected a vaccine of which all were from MAME background (43\%) out of those $50 \%$ were Asian, 20\% were black and 10\% from Middle East and $20 \%$ from other minority groups. Only $3 \%$ of participants had rejected a vaccine due to religious beliefs, $30 \%$ of vaccine refusal were due to fear, $10 \%$ were due to requiring more information on the vaccines and a further $10 \%$ questioned the safety of vaccines.

\section{Recommending vaccines to others}

Questions 6 and 7 looked at whether pharmacy students would recommend vaccinations to their friends and families, or children in their community. The majority (92\%) of participants agreed, with $45 \%$ of participants would recommend vaccines due to their belief that vaccines would protect them from diseases, and $26 \%$ would recommend vaccines as it would contribute to a reduction in the spread of harmful disease by reducing the risk of infections. This suggests that the students had a good understanding of the benefit of vaccination.

\section{MMR vaccines}

Question 9 looked into students' knowledge specifically about the MMR vaccine, and whether they can correctly identify the type of vaccine; $60 \%$ of participants answered correctly that it is a live-attenuated vaccine.

Students were then asked about the anti-vaccination movement claims, with $78 \%$ of participants correctly identified autism, a further $13 \%$ of participants answered blindness. The antivaccination movement does not declare a link between blindness and the MMR vaccine. Others indicated diabetes (4\%), heart failure $(3 \%)$ and deafness $(1 \%)$. All participants from a white background answered correctly (autism), comparatively, 69\% of Asian participants responded correctly. When participants were asked if they believe there is link between MMR and autism, the majority were not sure if it is true or false (fig. 2).

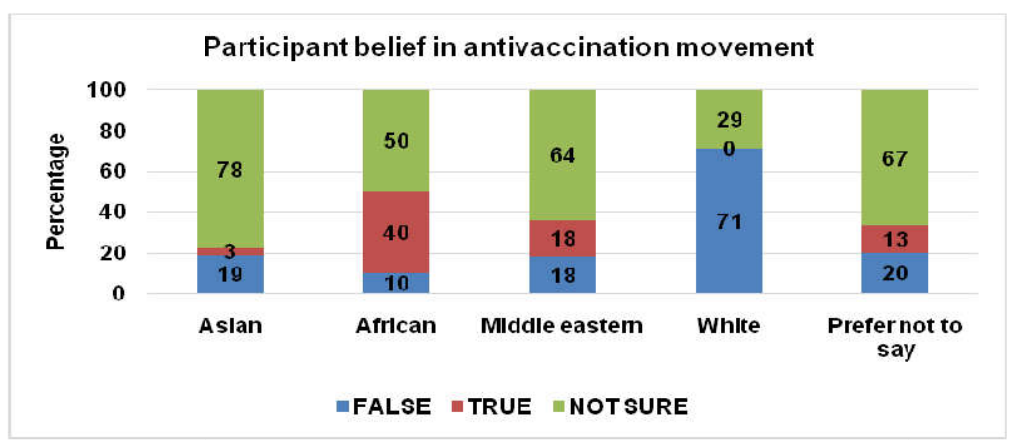

Fig. 2: Bar chart displaying personal beliefs on antivaccination movement based on ethnicity

Table 1 is a list of myths that WHO has published. These six common misconceptions regarding vaccinations are often mentioned when parents are deciding whether to have their children vaccinated. This study used those statements to assess the pharmacy students level of knowledge. None of the participants identified that they were all myths.

Table 1: Participant response on whether they believed statements to be true or false

\begin{tabular}{|c|c|c|c|}
\hline \multirow[t]{2}{*}{ Myth } & \multicolumn{3}{|c|}{ Participants who answered (\%) } \\
\hline & True & False & Unsure \\
\hline $\begin{array}{l}\text { The diseases had already begun to disappear before vaccines were introduced, because of better hygiene and } \\
\text { sanitation. }\end{array}$ & 27 & 39 & 34 \\
\hline $\begin{array}{l}\text { There are several vaccines that have been associated with more adverse events and deaths than others. } \\
\text { Parents should not allow their children to receive those vaccinations. }\end{array}$ & 20 & 48 & 32 \\
\hline Vaccines cause many harmful side effects and possible long-term effects we don't even know about. & 19 & 47 & 34 \\
\hline $\begin{array}{l}\text { Vaccine preventable diseases have been virtually eliminated from my country, so there is no need for my } \\
\text { child to be vaccinated. }\end{array}$ & 9 & 76 & 15 \\
\hline $\begin{array}{l}\text { Giving a child multiple vaccination for different diseases at the same time increases the risk of harmful side } \\
\text { effects and can overload the immune system }\end{array}$ & 40 & 27 & 33 \\
\hline The majority of people who get diseases have been vaccinated & 35 & 33 & 32 \\
\hline
\end{tabular}

The final question was intended to allow participants the opportunity to mention other resources they would find useful to find further information regarding vaccines. None of the participants mentioned The Green Book (UK only), which is a freely available to all health professionals (fig. 3).

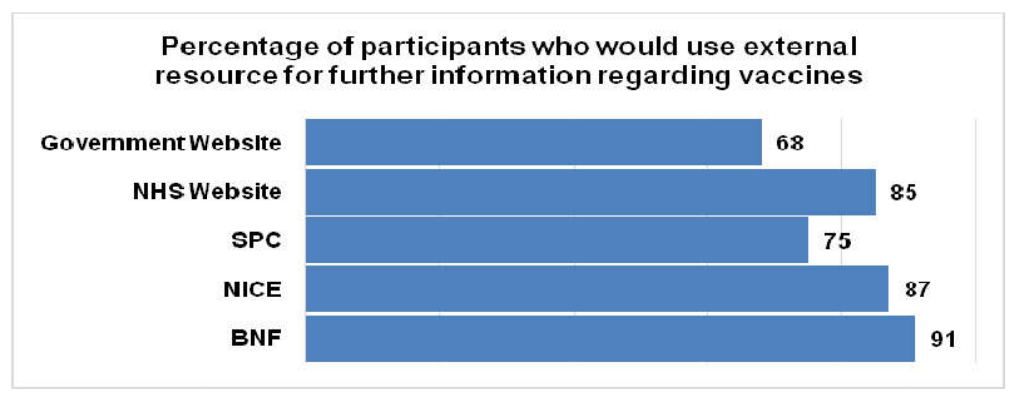

Fig. 3: Funnel chart displaying participants choice for looking at further information regarding vaccines, BNF: British National Formulary, NICE: National Institute for Clinical Excellence, SPC: Summary of Medicinal Product Characteristics, NHS: National Health Services 


\section{DISCUSSION}

To have a successful informative conversation with a patient it is essential that pharmacists are aware of both the facts and the myths about vaccinations that people may have access to. This study elucidates that undergraduate pharmacy students appear not to be fully prepared to discuss these controversies as they lack knowledge of the myths. Only $60 \%$ of the participants accurately identified the type of product that MMR vaccine is. A small number $(28 \%)$ of participants believed the anti-vaccination movement was false, the rest were either unsure or believed the anti-vaccination movement [21]. Female participants formed the majority (65\%) of participants.

For this study, a questionnaire-based approach was chosen. Open, closed and multiple options questions were used. Open questions (explanation boxes) were not completed by approximately $70 \%$ of participants, for example, participants who indicated that they would not be recommending vaccines did not explain why. This questions future advice to assist their clients' decision to accept vaccinations as they did not elaborate their reasons.

This also casts doubt on the veracity of their responses; for example $41 \%$ of male participants claimed they had received the HPV vaccine, which was not routinely offered to this patient group until very recently.

\section{Reliability and validity of the questionnaire}

The participants were asked the same questions, in the same order. All were at the same level of education and collusion may have occurred. As an undergraduate project, the questionnaire was not replicated on a separate group of participants to check reliability, and thus, the consistency of results is questionable. However, the results generated identified concerning gaps in knowledge, as intended in the project aim

After participants returned the completed questionnaire, they were provided information leaflets regarding vaccines and were also informed of sources where they could find further information. This would address the gaps in knowledge identified and prompt them to learn more about vaccine information and mis-information Understanding the myths will engender confidence in addressing patients' future questions surrounding vaccines, on the frontline of community medicine. The gaps were also shared with the course coordinators for curriculum development.

\section{CONCLUSION}

A concerning number of pharmacy students could not identify common myths surrounding vaccines, nor identify the type of vaccine used in MMR. The curriculum should be revised to improve pharmacists' knowledge for future practice. Future studies should be considered to ensure any improvements are measured and to eliminate the cohort effect.

\section{FUNDING}

Nil

\section{AUTHORS CONTRIBUTIONS}

All the authors have contributed equally.

\section{CONFLICTS OF INTERESTS}

The authors declare no conflict of interest.

\section{REFERENCES}

1. Casiday R. Children's health and the social theory of risk Insights from the British measles, mumps and rubella (MMR) controversy. Soc Sci Med 2007;65:1059-70.
2. Centres for Disease Control and Prevention. Measles, Mumps, Rubella (MMR) Vaccines; 2013. Available from: https://www.cdc.gov/vaccinesafety/vaccines/mmrvaccine.html [Last accessed on 05 Mar 2020]

3. Chen R, DeStefano F. Negative association between MMR and autism. Lancet 1999;353;1987-8.

4. Demicheli V, Rivetti A, Debalini M, Pietrantonj C. Cochrane database of systematic reviews; 2012. Available from: https://www.cochranelibrary.com/cdsr/doi/10.1002/146518 58.CD 004407.pub3/abstract [Last accessed on 09 Mar 2020]

5. Evans M, H Stoddart H, Condon L, Freeman E, Grizzell M, Mullen R. Parents' perspectives on the MMR immunisation: a focus group study. Br J General Practice 2001;51:904-10.

6. Funk S. Critical immunity thresholds for measles elimination, London: Cmmid; 2017.

7. Gov UK. Measles in England; 2019. Available from: https://publichealthmatters.blog.gov.uk/2019/08/19/measles -in-england/ [Last accessed on 14 Mar 2020]

8. Harling H, White JM, Ramsay ME, Macsween KF, Van den Bosch C. The effectiveness of the mumps component of the MMR vaccine: a case control study. Vaccine 2005;23:4070-4.

9. Hilton S, Petticrew M, Hunt K. Parents' champions vs. vested interests: Who do parents believe about MMR? A qualitative study. BMC Public Health; 2007. p. 7.

10. Hilton S, Petticrew M, Hunt K. Combined vaccines are like a sudden onslaught to the body's immune system': parental concerns about vaccine 'overload' and 'immune-vulnerability'. Vaccine 2006;3:7.

11. National Health Services (NHS). Fall in coverage for all routine childhood vaccinations in England in 2018-19. Available from: https://digital.nhs.uk/news-and-events/latest-

news/childhood-vaccination-coverage-statistics-2018-19 [Last accessed on 09 Mar 2020]

12. National Institute of Clinical Excellence (NICE). Immunizationschildhood; $2020 . \quad$ Available from: https://cks.nice.org.uk/immunizations-childhood\#!scenario:1 [Last accessed on 10 Mar 2020]

13. Plotkin S, Orenstein W, Offit P, Edwards K. Plotkin's vaccines. Infectious Disease 2017;7:50-62.

14. Practice Business. Inside the anti-vaxxer movement; 2019 Available from: https://practicebusiness.co.uk/inside-the-antivaxxer-movement/ [Last accessed on 13 Mar 2020]

15. Religious Tolerance. About the Jehovah's Witnesses Christian denomination; 2002. Available from: http://www.religioustolerance.org/witness6.htm [Last accessed on 11 Mar 2020]

16. Sathyanarayana Rao TS, Andrade C. The MMR vaccine and autism: sensation, refutation, retraction, and fraud. Indian J Psychiatry 2011;53:95

17. Schoenbohm R. How measles can change a life; 2019. Available from: https://www.vaccinestoday.eu/stories/how-measlescan-change-a-life/ [Last accessed on 04 Mar 2020]

18. Stewart M. Measles, mumps and rubella (MMR) vaccine (MM Rvax Pro, Priorix); 2020. Available from: https://patient.info/medicine/measles-mumps-and-rubella-mmrvaccine-mmrvaxpro-priorix [Last accessed on 05 Mar 2020]

19. Wakefield AJ, Murch SH, Anthony A, Linnell J, Casson DM, Malik $\mathrm{M}$, et al. Ileal-lymphoid-nodular hyperplasia, non-specific colitis, and pervasive developmental disorder in children. Lancet 1998;351:637-41.

20. World Health Organisation (WHO). Six common misconceptions about immunization; 2020. Available from: https://www.who.int/vaccine_safety/initiative/detection/imm unization_misconceptions/en/ [Last accessed on 14 Mar 2020]

21. Yung CF, Andrews N, Bukasa A, Brown KE, Ramsay M. Mumps complications and effects of mumps vaccination, England and Wales, 2002-2006. Emergency Infectious Disease 2011;4:661-7. 